\title{
Lymph Node Abscess
}

National Cancer Institute

\section{Source}

National Cancer Institute. Lymph Node Abscess. NCI Thesaurus. Code C99091.

An abscess that develops in a lymph node and the surrounding tissues as a result of an infectious process. The affected lymph node is palpable and tender. 